\title{
Nanoscale Ru(0) Particles: Arene Hydrogenation Catalysts in Imidazolium Ionic Liquids
}

\author{
Martin H. G. Prechtl, ${ }^{\dagger}$ Morgana Scariot, ${ }^{\dagger}$ Jackson D. Scholten, ${ }^{\dagger}$ Giovanna Machado, ${ }^{\dagger, \S}$ \\ Sérgio R. Teixeira, ${ }^{\ddagger}$ and Jairton Dupont ${ }^{\star, \dagger}$ \\ Laboratory of Molecular Catalysis, Institute of Chemistry, Universidade Federal do Rio Grande \\ do Sul, Av. Bento Gonçalves 9500, Porto Alegre, CEP 91501-970, RS, Brazil, Institute of Physics, \\ Universidade Federal do Rio Grande do Sul, Av. Bento Gonçalves 9500, Porto Alegre, \\ CEP 91501-970, RS, Brazil, and Universidade de Caxias do Sul, Departamento de Engenharia \\ Química, Rua Francisco Getúlio Vargas, 1130, Caxias do Sul 95070-560, RS, Brazil
}

Received June 2, 2008

\begin{abstract}
The reduction of $\left[\mathrm{Ru}(\mathrm{COD})(2 \text {-methylally })_{2}\right](\mathrm{COD}=1,5$-cyclooctadiene) dispersed in various room-temperature ionic liquids (ILs), namely, 1-n-butyl-3-methylimidazolium (BMI) and 1-n-decyl-3-methylimidazolium (DMI), associated with the $\mathrm{N}$-bis(trifluoromethanesulfonyl)imidates $\left(\mathrm{NTf}_{2}\right)$ and the corresponding tetrafluoroborates $\left(\mathrm{BF}_{4}\right)$ with hydrogen gas (4 bar) at $50^{\circ} \mathrm{C}$ leads to well-dispersed immobilized nanoparticles. Transmission electron microscopy (TEM) analysis of the particles dispersed in the ionic liquid shows the presence of $[R u(0)]_{n}$ nanoparticles (Ru-NPs) of 2.1-3.5 $\mathrm{nm}$ in diameter. Nanoparticles with a smaller mean diameter were obtained in the ILs containing the less coordinating anion $\left(\mathrm{NTf}_{2}\right)$ than that in the tetrafluoroborate analogues. The ruthenium nanoparticles in ionic liquids were used for liquid-liquid biphasic hydrogenation of arenes under mild reaction conditions $\left(50-90{ }^{\circ} \mathrm{C}\right.$ and 4 bar). The apparent activation energy of $E_{\mathrm{A}}=42.0 \mathrm{~kJ} \mathrm{~mol}^{-1}$ was estimated for the hydrogenation of toluene in the biphasic liquid-liquid system with Ru-NPs/BMI $\cdot \mathrm{NTf}_{2}$. TEM analysis of the ionic liquid material after the hydrogenation reactions shows no significant agglomeration of the $[R u(0)]_{n}$ nanoparticles. The catalyst ionic liquid phase can be reused several times without a significant loss in catalytic activity.
\end{abstract}

\section{Introduction}

Ionic liquids (ILs), ${ }^{1-6}$ in particular those based on the imidazolium cation, are emerging as alternative liquid templates for the generation of a plethora of size- and shapecontrolled nanostructures such as silicates and inorganic and hybrid nanoporous materials and nanoparticles (NPs). ${ }^{7-15}$

* Author to whom correspondence should be addressed. E-mail: dupont@iq.ufrgs.br.

' Institute of Chemistry, Universidade Federal do Rio Grande do Sul.

Institute of Physics, Universidade Federal do Rio Grande do Sul.

$\S$ Universidade de Caxias do Sul.

(1) Wasserscheid, P.; Keim, W. Angew. Chem., Int. Ed. 2000, 39, 3773.

(2) Fei, Z. F.; Geldbach, T. J.; Zhao, D. B.; Dyson, P. J. Chem.-Eur. J. 2006, 12, 2123

(3) Davis, J. H. Chem. Lett. 2004, 33, 1072.

(4) Welton, T. Coord. Chem. Rev. 2004, 248, 2459.

(5) Endres, F.; El Abedin, S. Z. Phys. Chem. Chem. Phys. 2006, 8, 2101.

(6) Dupont, J.; Consorti, C. S.; Spencer, J. J. Braz. Chem. Soc. 2000, 11, 337.

(7) Wang, L.; Chang, L. X.; Zhao, B.; Yuan, Z. Y.; Shao, G. S.; Zheng, W. J. Inorg. Chem. 2008, 47, 1443.

(8) Antonietti, M.; Kuang, D. B.; Smarsly, B.; Yong, Z. Angew. Chem., Int. Ed. 2004, 43, 4988.
Indeed, these liquids possess preorganized structures that can adapt or are adaptable to many species, as they provide hydrophobic or hydrophilic regions. ${ }^{16,17}$ In this respect, it has been recently reported that the size of "soluble" metal nanoparticles is directly related to ionic liquid self-organization and thus can in principle be tuned by modulating the reaction temperature, ${ }^{18}$ length of the $\mathrm{N}$-alkyl imidazolium sides chains, ${ }^{19}$ or anion volume. ${ }^{20,21}$ Moreover, transition-

(9) Taubert, A.; Li, Z. Dalton Trans. 2007, 723.

(10) Migowski, P.; Dupont, J. Chem.-Eur. J. 2007, 13, 32.

(11) Wang, Y.; Yang, H. Chem. Commun. 2006, 2545.

(12) Wang, Y.; Yang, H. J. Am. Chem. Soc. 2005, 127, 5316.

(13) Trewyn, B. G.; Whitman, C. M.; Lin, V. S. Y. Nano Lett. 2004, 4, 2139.

(14) Zhao, D. B.; Fei, Z. F.; Ang, W. H.; Dyson, P. J. Small 2006, 2, 879.

(15) Endres, F.; El Abedin, S. Z. Phys. Chem. Chem. Phys. 2002, 4, 1649.

(16) Dupont, J. J. Braz. Chem. Soc. 2004, 15, 341.

(17) Dupont, J.; Suarez, P. A. Z. Phys. Chem. Chem. Phys. 2006, 8, 2441.

(18) Gutel, T.; Garcia-Anton, J.; Pelzer, K.; Philippot, K.; Santini, C. C.; Chauvin, Y.; Chaudret, B.; Basset, J. M. J. Mater. Chem. 2007, 17, 3290.

(19) Migowski, P.; Machado, G.; Texeira, S. R.; Alves, M. C. M.; Morais, J.; Traverse, A.; Dupont, J. Phys. Chem. Chem. Phys. 2007, 9, 4814. 
Prechtl et al.

\section{Chart 1}
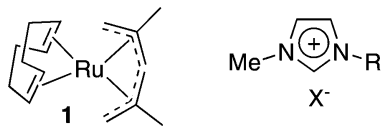

2, $\mathrm{X}=\mathrm{N}\left(\mathrm{SO}_{2} \mathrm{CF}_{3}\right)_{2}, \mathrm{R}=n$-butyl (BMI.NTf $\left.{ }_{2}\right)$

3, $\mathrm{X}=\mathrm{BF}_{4}, \mathrm{R}=n$-butyl $\left(\mathrm{BMI}^{\mathrm{B}} \mathrm{BF}_{4}\right)$

4, $\mathrm{X}=\mathrm{BF}_{4}, \mathrm{R}=n$-decyl $\left(\mathrm{DMI}^{\left.\mathrm{B} \mathrm{BF}_{4}\right)}\right.$

$5, \mathrm{X}=\mathrm{N}\left(\mathrm{SO}_{2} \mathrm{CF}_{3}\right)_{2}, \mathrm{R}=n$-decyl $\left(\mathrm{DMI} . \mathrm{NTf}_{2}\right)$

metal NPs in imidazolium ILs are stabilized by protective layers of discrete supramolecular $\left\{\left[(\mathrm{DAI})_{x}(\mathrm{X})_{x-n}\right]^{n+}\right.$ $\left.\left[(\mathrm{DAI})_{x-n}(\mathrm{X})_{x}\right]^{n-}\right\}_{n}(\mathrm{DAI}=$ dialkylimidazolium cation and $\mathrm{X}$ anion) species through the loosely bound anionic moieties or N-heterocycle carbenes together with an oxide layer when present on the metal surface. ${ }^{19,22-24}$ Other substances present in the media easily displace these loosely surface-bound protective species. This, on one hand, is responsible to some extent for their catalytic activity, but on the other hand, it explains their relatively low stability, which leads to aggregation/agglomeration and eventually to the bulk metal ${ }^{25}$ or facile oxidation in the case of $\mathrm{Ru}^{26,27}$ and $\mathrm{Co}^{28}$ nanoparticles, for example. In other cases, the metal nanoparticles are not stable and tend to aggregate, or alternatively, they serve as simple reservoirs of mononuclear catalytically active species. $^{29}$ In most of the cases, the catalytic properties (activity and selectivity) of these soluble metal nanoparticles are similar to those observed with classical heterogeneous catalysts; that is, they possess a pronounced surface like (multisite) rather than a single site like catalytic properties. $^{30,31}$ We report herein a simple organometallic approach ${ }^{32}$ for the synthesis and catalytic application of $\mathrm{Ru}(0)$ nanoparticles in imidazolium ionic liquids (Chart 1) using a clean straightforward hydrogenation route with the readily available versatile ruthenium precursor $\left[\mathrm{Ru}(\mathrm{COD})(2-\text { methylallyl })_{2}\right]$ (Chart 1). ${ }^{33-36}$ In most cases, the Ru-NPs are well dispersed and efficiently immobilized in the imidazolium ionic liquid

(20) Redel, E.; Thomann, R.; Janiak, C. Inorg. Chem. 2008, 47, 14

(21) Redel, E.; Thomann, R.; Janiak, C. Chem. Commun. 2008, 1789.

(22) Scholten, J. D.; Ebeling, G.; Dupont, J. Dalton Trans. 2007, 5554

(23) Scheeren, C. W.; Machado, G.; Teixeira, S. R.; Morais, J.; Domingos, J. B.; Dupont, J. J. Phys. Chem. B 2006, 110, 13011.

(24) Fonseca, G. S.; Machado, G.; Teixeira, S. R.; Fecher, G. H.; Morais, J.; Alves, M. C. M.; Dupont, J. J. Colloid Interface Sci. 2006, 301, 193.

(25) Umpierre, A. P.; Machado, G.; Fecher, G. H.; Morais, J.; Dupont, J. Adv. Synth. Catal. 2005, 347, 1404.

(26) Rossi, L. M.; Machado, G.; Fichtner, P. F. P.; Teixeira, S. R.; Dupont, J. Catal. Lett. 2004, 92, 149.

(27) Silveira, E. T.; Umpierre, A. P.; Rossi, L. M.; Machado, G.; Morais, J.; Soares, G. V.; Baumvol, I. L. R.; Teixeira, S. R.; Fichtner, P. F. P.; Dupont, J. Chem.-Eur. J. 2004, 10, 3734.

(28) Silva, D. O.; Scholten, J. D.; Gelesky, M. A.; Teixeira, S. e. R.; Santos, A. C. B. D.; Souza-Aguiar, E. F.; Dupont, J. ChemSusChem 2008, 1, 291.

(29) Cassol, C. C.; Umpierre, A. P.; Machado, G.; Wolke, S. I.; Dupont, J. J. Am. Chem. Soc. 2005, 127, 3298.

(30) Gelesky, M. A.; Chiaro, S. S. X.; Pavan, F. A.; dos Santos, J. H. Z.; Dupont, J. Dalton Trans. 2007, 5549.

(31) Fonseca, G. S.; Umpierre, A. P.; Fichtner, P. F. P.; Teixeira, S. R.; Dupont, J. Chem.-Eur. J. 2003, 9, 3263.

(32) Chaudret, B. C. R. Phys. 2005, 6, 117.

(33) Prechtl, M. H. G.; Ben-David, Y.; Giunta, D.; Busch, S.; Taniguchi, Y.; Wisniewski, W.; Gorls, H.; Mynott, R. J.; Theyssen, N.; Milstein, D.; Leitner, W. Chem.-Eur. J. 2007, 13, 1539.

(34) Holscher, M.; Prechtl, M. H. G.; Leitner, W. Chem.-Eur. J. 2007, 13, 6636 .

(35) Prechtl, M. H. G.; Holscher, M.; Ben-David, Y.; Theyssen, N.; Loschen, R.; Milstein, D.; Leitner, W. Angew. Chem., Int. Ed. 2007, $46,2269$.

(36) Giunta, D.; Holscher, M.; Lehmann, C. W.; Mynott, R.; Wirtz, C.; Leitner, W. Adv. Synth. Catal. 2003, 345, 1139.
Table 1. Particle Size (Determined by TEM) of Ruthenium Nanoparticles in IL (Ru/IL 6-9)

\begin{tabular}{ccc}
\hline \multicolumn{1}{c}{$\mathrm{Ru} / \mathrm{IL}$} & $\begin{array}{c}\text { particle size }[\mathrm{nm}] \\
\text { (before catalysis) }\end{array}$ & $\begin{array}{c}\text { particle size }[\mathrm{nm}] \\
\text { (after catalysis) }\end{array}$ \\
\hline $\mathrm{Ru} / \mathrm{BMI} \cdot \mathrm{NTf}_{2}, \mathbf{6}$ & $2.1 \pm 0.5$ & $2.8 \pm 0.6$ \\
$\mathrm{Ru} / \mathrm{BMI} \cdot \mathrm{BF}_{4}, \mathbf{7}$ & $2.9 \pm 0.5$ & $3.3 \pm 0.5$ \\
$\mathrm{Ru} / \mathrm{DMI} \cdot \mathrm{BF}_{4}, \mathbf{8}$ & $2.7 \pm 0.5$ & $3.1 \pm 0.5$ \\
$\mathrm{Ru} / \mathrm{DMI} \cdot \mathrm{NTf}_{2}, \mathbf{9}$ & $2.1 \pm 0.5$ & $3.5 \pm 0.5$
\end{tabular}

and do not separate from the liquid phase. Furthermore, we describe herein some kinetic insights for the multiphase hydrogenation of toluene, for which the activation energy has been estimated from the Arrhenius plot.

\section{Experimental Section}

General. All manipulations involving the ruthenium complex were carried out under an argon atmosphere using Schlenk or glovebox techniques. $\left[\mathrm{Ru}(\mathrm{COD})(2 \text {-methylallyl })_{2}\right]$ was obtained from Sigma-Aldrich and used without further purification. The ionic liquids $\left(\mathrm{BMI} \cdot \mathrm{NTf}_{2}, \mathrm{DMI} \cdot \mathrm{NTf}_{2}, \mathrm{BMI} \cdot \mathrm{BF}_{4}\right.$, and $\mathrm{DMI} \cdot \mathrm{BF}_{4} ; \mathrm{BMI}=$ 1- $n$-butyl-3-methylimidazolium, DMI = 1- $n$-decyl-3-methylimidazolium, $\mathrm{NTf}_{2}=N$-bis(trifluoromethanesulfonyl)imidates) were prepared according to known procedures. ${ }^{37}$ Arenes were degassed and stored under argon prior to use. All of the other chemicals were purchased from commercial sources and used without further purification. NMR spectra were recorded on a Varian VNMRs spectrometer (300 MHz). Mass spectra were obtained using a GC/ MS Shimadzu QP-5050 (EI, $70 \mathrm{eV}$ ). Gas chromatography analyses were performed with a Hewlett-Packard-5890 gas chromatograph with a flame ionization detector and a $30 \mathrm{~m}$ capillary column with a dimethylpolysiloxane stationary phase. Transmission electron microscopy (TEM) was performed on an EM 208S-Philips operating at $100 \mathrm{kV}$.

The nanoparticles' formation and catalytic hydrogenation reactions were carried out in a modified Fischer-Porter bottle immersed in a silicone oil bath and connected to a hydrogen reservoir. The substrates were added with a gastight precision Hamilton syringe $(1 \mathrm{~mL})$. The fall in the hydrogen pressure in the reservoir was monitored with a pressure transducer interfaced through a Novus converter to a PC, and the data were worked up via Microsoft Excel. The temperature was maintained at $50,60,75$, and $90{ }^{\circ} \mathrm{C}$ by a hot-stirring plate connected to a digital controller (ETS-D4 IKA). The catalyst/substrate ratio was calculated from the initial quantity of $\left[\mathrm{Ru}(\mathrm{COD})(2 \text {-methylallyl })_{2}\right]$ used.

Nanoparticles Formation. In a typical experiment, a FischerPorter bottle was loaded with $\left[\mathrm{Ru}(\mathrm{COD})(2-\text { methylallyl })_{2}\right](15 \mathrm{mg}$, $0.047 \mathrm{mmol})$ in the glovebox. Then, BMI $\cdot \mathrm{NTf}_{2}(1 \mathrm{~mL})$ was added via syringe under an argon flow. The mixture was stirred at room temperature for $60 \mathrm{~min}$, resulting in a turbid dispersion. The system was heated to $50{ }^{\circ} \mathrm{C}$, and hydrogen (4 bar) was admitted to the system. After stirring for $18 \mathrm{~h}$, a black suspension was obtained. The Fischer-Porter bottle was then kept under reduced pressure to eliminate the cyclooctane and isobutane formed. The $\mathrm{Ru}$ nanoparticles embedded in the ionic liquid were analyzed by TEM and used for catalytic experiments (see below).

Hydrogenations. Liquid-Liquid Biphasic. The arene (e.g., 1 $\mathrm{mL}$ toluene; $9.5 \mathrm{mmol}$ ) was added to the ionic catalytic solution obtained as described, and hydrogen was admitted to the system at a constant pressure (see Table 1). At the end of the indicated reaction time, the sample was analyzed by gas chromatography/

(37) Cassol, C. C.; Ebeling, G.; Ferrera, B.; Dupont, J. Adv. Synth. Catal. 2006, 348, 243. 
Scheme 1. Direct Hydrogenation of Ruthenium Precursor 1 with Molecular Hydrogen in Imidazolium Ionic Liquids 2-5 Yielding the Ru-NP Colloidal Solutions 6-9

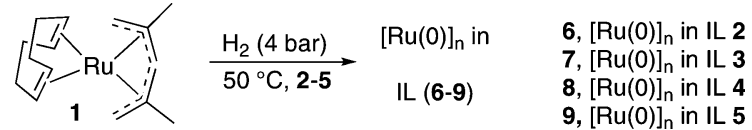

gas chromatography mass spectrometry (GC/GC-MS). The reaction mixture forms an emulsion, and at the end of the reaction, a typical two-phase system was obtained, where the lower phase contains the $\mathrm{Ru}$ nanoparticles in the ionic liquid and the upper phase contains the organic layer. The organic phase was separated quantitatively by heating $\left(70{ }^{\circ} \mathrm{C}\right)$ the reaction mixture for 30-60 min under reduced pressure, and the volatile compounds were condensed in a cold trap (cooled with liquid nitrogen). An aliquot was analyzed by GC/GC-MS.

Sample Preparation for TEM Analysis. In order to perform the TEM analysis, a droplet of the suspensions containing the $\mathrm{Ru}$ nanoparticles embedded in the ILs was dispersed in isopropanol, and a slight amount of this dispersion was placed in a carbon-coated copper grid. Particle size distributions were determined once the original negative had been digitalized. The nanoparticles' diameter was estimated from ensembles of 200 particles (400 counts) chosen in arbitrary areas of the enlarged micrographs. The diameters of the particles in the micrographs were measured using the software Sigma Scan Pro 5.

\section{Results and Discussion}

The ruthenium nanoparticles were obtained by a simple reduction of $\left[\operatorname{Ru}(\mathrm{COD})(2 \text {-methylallyl })_{2}\right], \mathbf{1}$, dispersed or dissolved in imidazolium ionic liquids $\mathbf{2}-\mathbf{5}$, under 4 bar of hydrogen gas at $50{ }^{\circ} \mathrm{C}$ (Scheme 1). As recently reported by Santini and co-workers, the size of Ru-NPs synthesized in
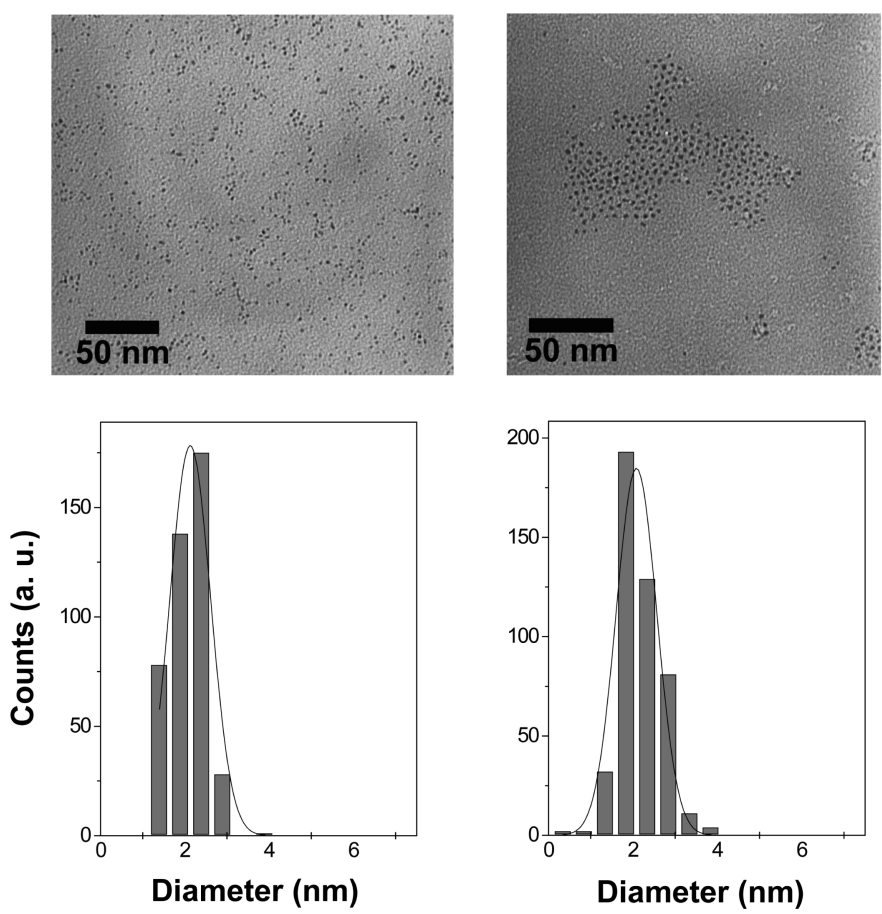

(a)

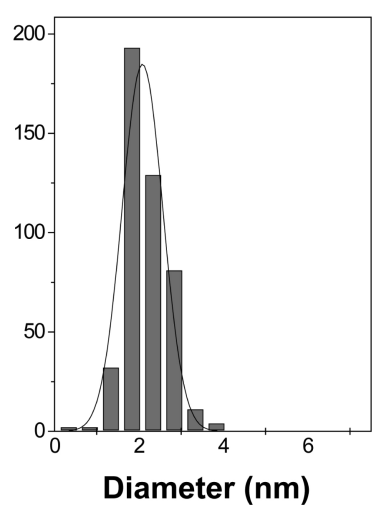

(b)

ILs varies between 0 and $25^{\circ} \mathrm{C}$, where lower temperatures resulted in smaller particles (ca. $1 \mathrm{~nm}$ ) and higher temperatures $\left(25-75^{\circ} \mathrm{C}\right)$ resulted in slightly larger particles $(2-3$ $\mathrm{nm}),{ }^{18}$ which is inverse to those prepared in organic solvents. ${ }^{38}$ Nevertheless, we decided to use higher temperature $\left(50{ }^{\circ} \mathrm{C}\right)$ because it is also well-known that at $0{ }^{\circ} \mathrm{C}$ smallsize nanoparticles easily agglomerate, at least partially. ${ }^{39}$ Furthermore, the high viscosity at low temperatures of some of the here-used ILs plays an important role.

The initial white to off-white suspensions of $\mathbf{1}$ in ILs (previously stirred for $1 \mathrm{~h}$ under argon) turned black under hydrogen gas within $15 \mathrm{~min}$ in the case of the BMI-ILs 2 (BMI-NTf ${ }_{2}$ : 1- $n$-butyl-3-methylimidazolium $N$-bis(trifluoromethanesulfonyl)imidate) and $\mathbf{3}\left(\mathrm{BMI} \cdot \mathrm{BF}_{4}\right.$ : 1-n-butyl-3methylimidazolium tetrafluoroborate). For the DMI-ILs 4 $\left(\mathrm{DMI} \cdot \mathrm{BF}_{4}\right.$ : 1-n-decyl-3-methylimidazolium tetrafluoroborate) and $5\left(\mathrm{DMI} \cdot \mathrm{NTf}_{2}\right.$ : 1- $n$-decyl-3-methylimidazolium $\mathrm{N}$-bis(trifluoromethanesulfonyl)imidate), a prolonged reaction time was needed until the mixture turned black. Moreover, complex $\mathbf{1}$ is totally soluble in $\mathrm{DMI} \cdot \mathrm{NTf}_{2}, \mathbf{5}$. After stirring for $18 \mathrm{~h}$, the black colloidal suspension of Ru-NPs (6-9) was isolated from cyclooctane and isobutane under a vacuum and then kept under an argon atmosphere at room temperature. In most cases, the Ru-NPs could not be separated from the ILs (suspensions $\mathbf{6 , 8}$, and $\mathbf{9}$ ) by centrifugation or the addition of solvents. In the case of colloidal suspension 7 $\left(\mathrm{Ru}-\mathrm{NPs} / \mathrm{BMI} \cdot \mathrm{BF}_{4}\right)$, the addition of acetone leads to separation of the nanoparticles from the IL. These observations for colloidal suspension $6\left(\mathrm{Ru}-\mathrm{NPs} / \mathrm{BMI} \cdot \mathrm{NTf}_{2}\right.$, inseparable $\mathrm{Ru}-\mathrm{NPs})^{18}$ and colloidal suspension $7\left(\mathrm{Ru}-\mathrm{NPs} / \mathrm{BMI}^{1} \mathrm{BF}_{4}\right.$; separable Ru-NPs) ${ }^{27}$ are in agreement with previous reports
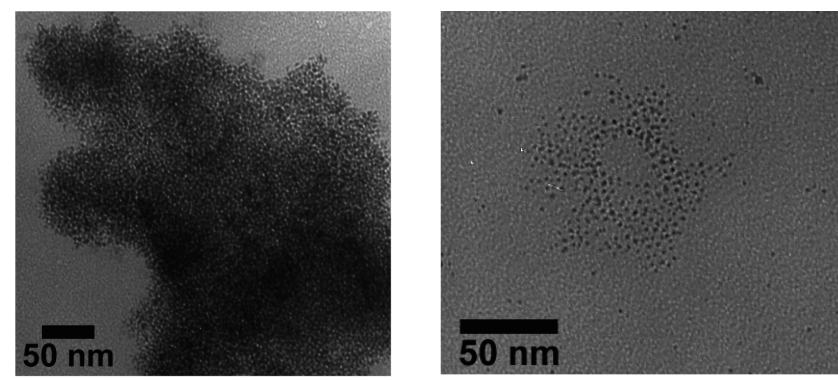

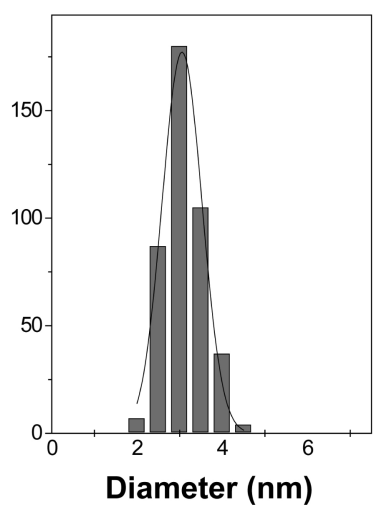

(c)

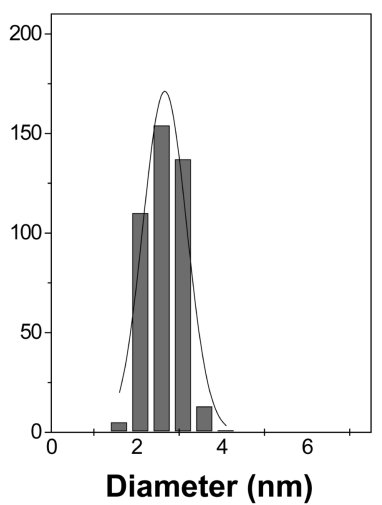

(d)

Figure 1. Selected in situ TEM images of the ruthenium nanoparticles in (a) BMI $\cdot \mathrm{NTf}_{2}$, (b) $\mathrm{DMI} \cdot \mathrm{NTf}_{2}$, (c) $\mathrm{BMI} \cdot \mathrm{BF}_{4}$, and $(\mathrm{d}) \mathrm{DMI} \cdot \mathrm{BF} 4$ before the catalytic hydrogenation of toluene. 

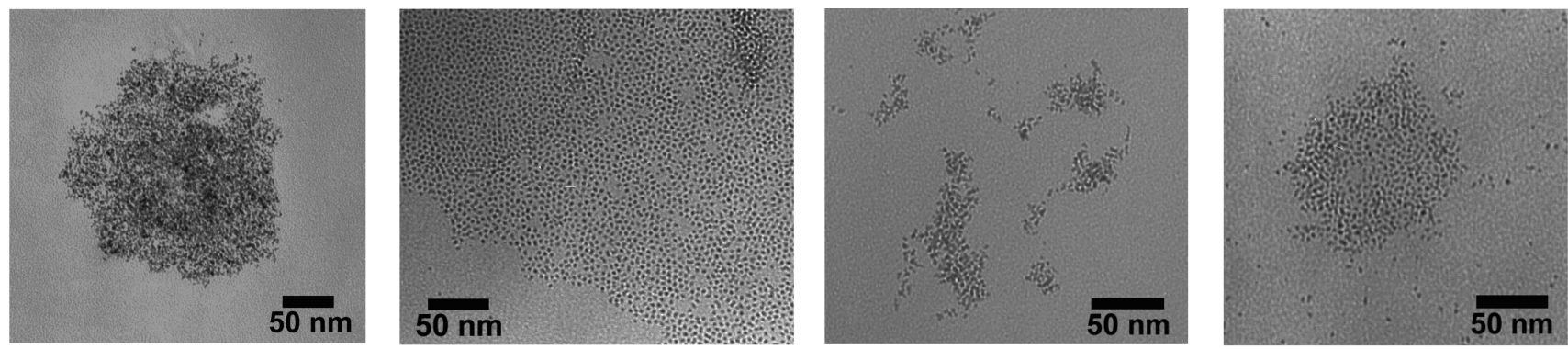

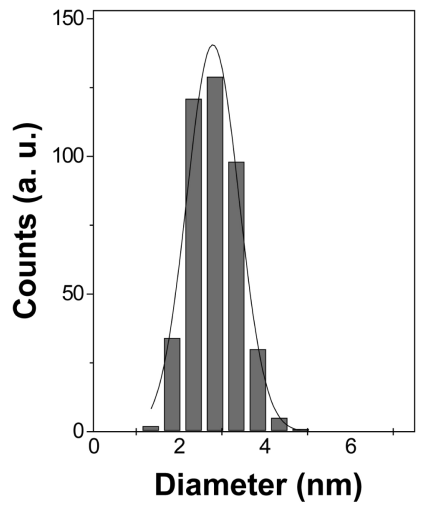

(a)

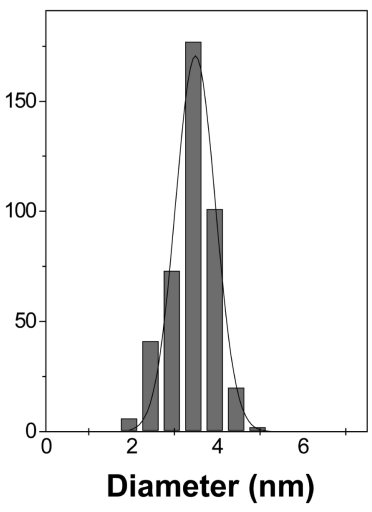

(b)

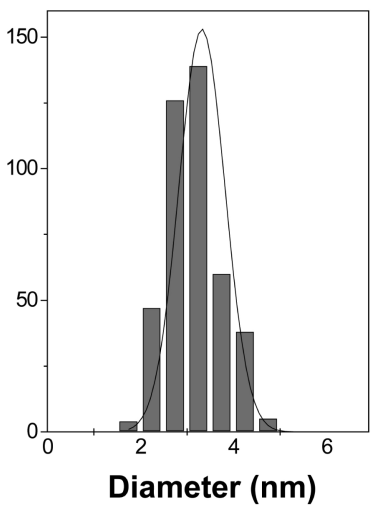

(c)

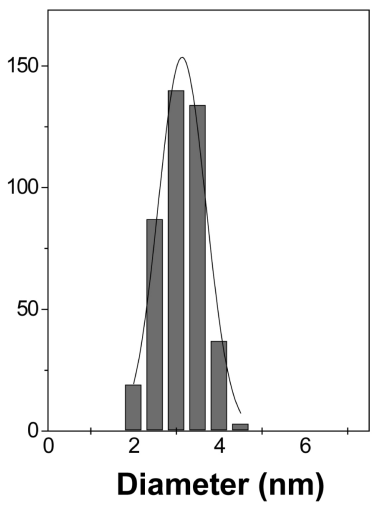

(d)

Figure 2. Selected in situ TEM images of the ruthenium nanoparticles in (a) BMI $\cdot \mathrm{NTf}_{2}$, (b) $\mathrm{DMI} \cdot \mathrm{NTf}_{2}$, (c) $\mathrm{BMI} \cdot \mathrm{BF}_{4}$, and $(\mathrm{d}) \mathrm{DMI} \cdot \mathrm{BF} 4$ after the catalytic hydrogenation of toluene.

Scheme 2. Hydrogenation of Arenes with Ru-NP Ionic Liquid Colloidal Suspensions (6-9)

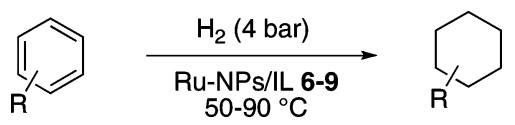

obtained for the decomposition of $[\mathrm{Ru}(\mathrm{COD})(\mathrm{COT})](\mathrm{COT}=$ 1,3,5-cyclooctatriene) in 1- $n$-butyl-3-methylimidazolium ILs such as $\mathrm{BMI} \cdot \mathrm{NTf}_{2}{ }^{18}$ and $\mathrm{BMI} \cdot \mathrm{BF}_{4} \cdot{ }^{27}$ The colloidal suspensions of the Ru-NPs $(\mathbf{6}, \mathbf{8}$, and $\mathbf{9})$ are stable for weeks, in opposition to suspension $7\left(\mathrm{Ru}-\mathrm{NPs} / \mathrm{BMI} \cdot \mathrm{BF}_{4}\right)$, which separates after standing for 3-7 days. These observations allow two conclusions: for Ru-NPs, the least coordinating anion, $\mathrm{NTf}_{2},{ }^{40}$ (IL 2) prevents separation of the particles better than $\mathrm{BF}_{4}$ in IL 3. On the other hand, this effect is compensated by substituting the BMI cation with the DMI cation (IL 4), which also provides a stable colloidal suspension, even in the presence of the $\mathrm{BF}_{4}$ anion. As a consequence, all samples of Ru-NPs were analyzed by TEM in the corresponding ionic liquids $\mathbf{2}-\mathbf{5}$ before being used in catalysis and after several catalytic recycles. All obtained TEM images before and after catalysis (Figures 1 and 2) show a narrow size distribution and no significant agglomeration, independently of the reaction media (Figures 1 and 2, Table 1). The histograms (Figures 1 and 2) show the resulting particle size distributions that can be reasonably well-fitted by a Gaussian curve. In the cases of the tetrafluoroborate imidazolium ILs, the mean particle size (2.7-3.3 $\mathrm{nm}$, Table 1) remains unchanged within the standard variation $(0.5-0.6 \mathrm{~nm})$ before and after catalysis ( 7 and $\mathbf{8})$. However, the system Ru-NPs/DMI $\cdot \mathrm{NTf}_{2}, \mathbf{9}$, shows slightly higher variation of the particle size after application in catalysis.
Before catalysis, the mean particle size in this system is 2.1 $\pm 0.5 \mathrm{~nm}$, and after catalysis, the mean value increases to $3.5 \pm 0.5 \mathrm{~nm}$. This observation stays in agreement with previous reports, according to which the smallest particles tend to agglomerate more easily than larger ones. ${ }^{18,39}$ Interestingly, the mean diameter of the nanoparticles is influenced by the nature of the anion. Indeed, before or after catalysis (see Table 1), smaller nanoparticles were obtained in the ILs containing the less coordinating anion $\left(\mathrm{NTf}_{2}\right)$ than those in the tetrafluoroborates analogue nanoparticles, which possess a larger mean diameter.

The dimension of particle size (around $3.0 \mathrm{~nm}$ ) of these nanoparticles is similar to that observed for the nanoparticles prepared by the decomposition of $[\mathrm{Ru}(\mathrm{COD})(\mathrm{COT})]^{18,27}$ or the reduction of ruthenium oxide ${ }^{26,41}$ dispersed in imidazolium ILs. The narrow size distribution and low agglomeration of the small Ru-NPs in the ILs 2, 4, and $\mathbf{5}$ indicate the good properties of these ILs for the synthesis, immobilization, and stabilization of Ru-NPs. Interestingly, attempts to analyze the ruthenium nanoparticles dispersed in $\mathrm{BMI} \cdot \mathrm{NTf}_{2}$ by in situ X-ray diffraction techniques failed since it is difficult to observe Bragg reflections of the metal nanoparticles due to high X-ray absorption of the IL. ${ }^{42}$

(38) Pelzer, K.; Vidoni, O.; Philippot, K.; Chaudret, B.; Colliere, V. Adv. Funct. Mater. 2003, 13, 118.

(39) Li, D.; Kaner, R. B. J. Am. Chem. Soc. 2006, 128, 968.

(40) Gaillard, C.; Billard, I.; Chaumont, A.; Mekki, S.; Ouadi, A.; Denecke, M. A.; Moutiers, G.; Wipff, G. Inorg. Chem. 2005, 44, 8355.

(41) Rossi, L. M.; Dupont, J.; Machado, G.; Fichtner, P. F. P.; Radtke, C.; Baumvol, I. J. R.; Teixeira, S. R. J. Braz. Chem. Soc. 2004, 15 904.

(42) Machado, G.; Scholten, J. D.; de Vargas, T.; Teixeira, S. R.; Ronchi, L. H.; Dupont, J. Int. J. Nanotechn. 2007, 4, 541. 
Table 2. Liquid-Liquid Biphasic Hydrogenation of Arenes with the Ru-NPs/IL 6-9 ${ }^{a}$

\begin{tabular}{|c|c|c|c|c|c|c|c|}
\hline entry & $\mathrm{Ru} / \mathrm{IL}$ & arene/Ru & substrate & product & $t(\mathrm{~h})$ & $T\left({ }^{\circ} \mathrm{C}\right)$ & $\mathrm{cv}(\%)$ \\
\hline 1 & 6 & 200 & toluene & methylcyclohexane & $3 / 18$ & 75 & $37 / 85$ \\
\hline 2 & 6 & 200 & $o$-xylene & 1,2-dimethylcyclohexane & 18 & 75 & 32 \\
\hline 3 & 6 & 200 & $m$-xylene & 1,3-dimethylcyclohexane & 18 & 75 & 21 \\
\hline 4 & 6 & 200 & $p$-xylene & 1,4-dimethylcyclohexane & 18 & 75 & 31 \\
\hline 5 & 6 & 200 & $t$ Bu-benzene & $t$ Bu-cyclohexane & 18 & 75 & 20 \\
\hline 6 & 6 & 200 & toluene & methylcyclohexane & 3 & 90 & 67 \\
\hline 7 & 6 & 200 & toluene & methylcyclohexane & $3 / 24$ & 60 & $17 / 59$ \\
\hline 8 & 6 & 200 & toluene & methylcyclohexane & $3 / 24$ & 50 & $13 / 50$ \\
\hline 9 & 6 & 300 & toluene & methylcyclohexane & $3 / 24$ & 75 & $41 / 78$ \\
\hline 10 & 6 & 400 & toluene & methylcyclohexane & $3 / 42$ & 75 & $39 / 72$ \\
\hline 11 & 6 & 100 & toluene & methylcyclohexane & 3 & 75 & 39 \\
\hline 12 & 6 & 50 & toluene & methylcyclohexane & 3 & 75 & 43 \\
\hline 13 & 7 & 200 & toluene & methylcyclohexane & 18 & 75 & 40 \\
\hline 14 & 8 & 200 & toluene & methylcyclohexane & 18 & 75 & 76 \\
\hline 15 & 9 & 200 & toluene & methylcyclohexane & $3 / 18$ & 75 & $51 / 90$ \\
\hline
\end{tabular}

${ }^{a}$ Reaction conditions: Ru/IL (15 mg [Ru(COD)(2-methylallyl) 2$], 1,1 \mathrm{~mL} \mathrm{IL;} \mathrm{substrate/cat.}=200: 1=9.5 \mathrm{mmol}$ substrate (e.g., $1 \mathrm{~mL}$ toluene), $400: 1=$ $19.0 \mathrm{mmol}, 300: 1=14.25 \mathrm{mmol}, 100: 1=4.75 \mathrm{mmol}, 50: 1=2.38 \mathrm{mmol}$; Ru-NPs/BMI$\cdot \mathrm{NTf}_{2}(\mathbf{6}), \mathrm{Ru}-\mathrm{NPs} / \mathrm{BMI} \cdot \mathrm{BF} 4(\mathbf{7}), \mathrm{Ru}-\mathrm{NPs} / \mathrm{DMI} \cdot \mathrm{BF} 4(\mathbf{8}), \mathrm{Ru}-\mathrm{NPs} /$ $\mathrm{DMI} \cdot \mathrm{NTf}_{2}(\mathbf{9})$

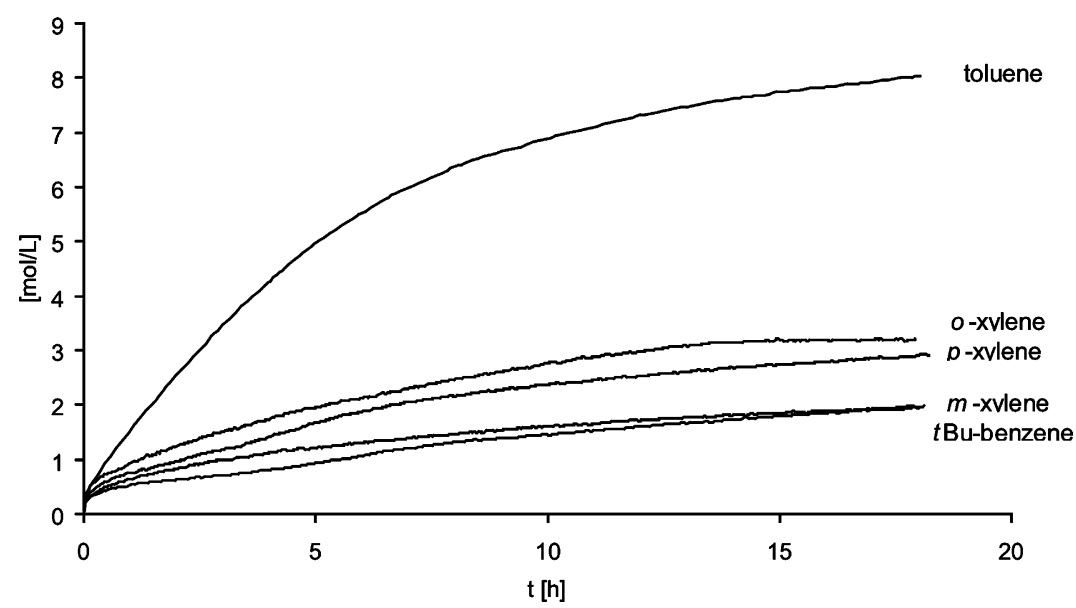

Figure 3. Hydrogenation of arenes with the colloidal suspension Ru-NPs/BMI $\cdot \mathrm{NTf}_{2}, 6(\operatorname{arene} / \mathrm{Ru}=200)$ at $75{ }^{\circ} \mathrm{C}(\mathrm{Table} 2)$.

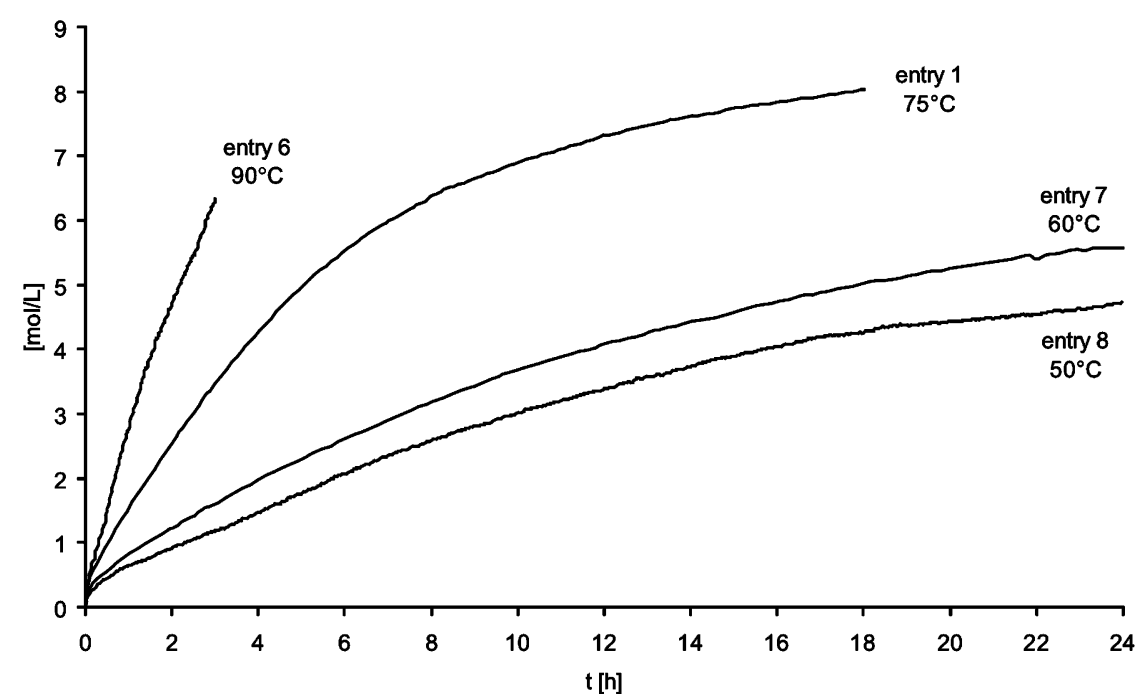

Figure 4. Conversion of toluene to methylcyclohexane between 50 and $90{ }^{\circ} \mathrm{C}$ (entries $1,6-8$, Table 2).

The catalytic properties of ionic solution 6 (Ru-NPs/ $\mathrm{BMI} \cdot \mathrm{NTf}_{2}$ ) in a liquid-liquid biphasic system were tested in the hydrogenation of arenes under different reaction conditions (Scheme 2, Table 2). The hydrogen consumption was used for monitoring the hydrogenation reactions. The data obtained for the hydrogenation of toluene were then used to estimate the activation energy according to Arrhenius law. Furthermore, the other catalytic ionic solutions 7-9 were tested under different reaction conditions in the hydrogenation of toluene (Table 2). 


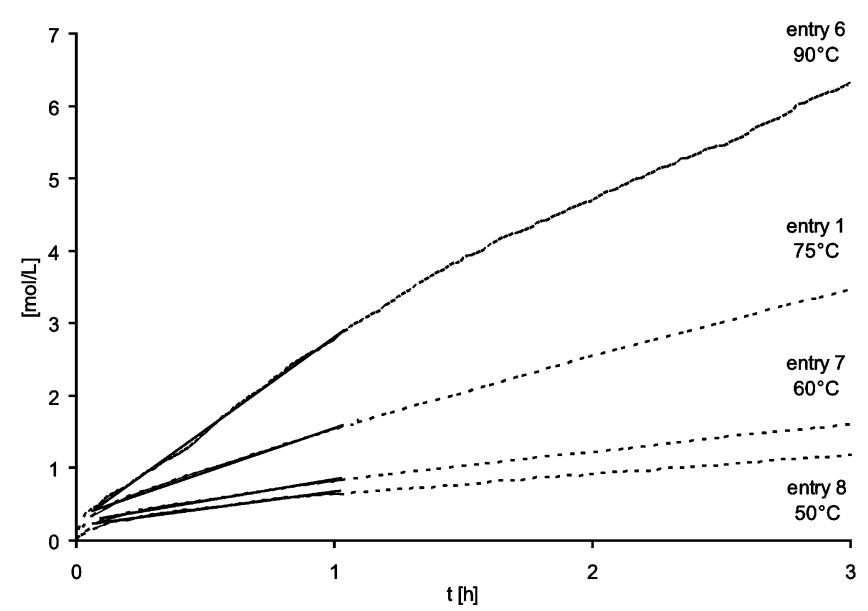

Figure 5. The initial periods of the hydrogenation of toluene are depicted. The slopes of the linear parts were used to calculate the initial rates. $k_{90^{\circ} \mathrm{C}}$ $=2.57\left[\mathrm{~mol} \mathrm{~L}^{-1} \mathrm{~h}^{-1}\right]$ (entry 6), $k_{75^{\circ} \mathrm{C}}=1.22\left[\mathrm{~mol} \mathrm{~L}^{-1} \mathrm{~h}^{-1}\right]$ (entry 1$), k_{60^{\circ} \mathrm{C}}$ $=0.60\left[\mathrm{~mol} \mathrm{~L}^{-1} \mathrm{~h}^{-1}\right]$ (entry 7), $k_{50^{\circ} \mathrm{C}}=0.48\left[\mathrm{~mol} \mathrm{~L}^{-1} \mathrm{~h}^{-1}\right]$ (entry 8) (Table 2).

Table 3. Initial Rates of the Toluene Hydrogenation between 50 and 90 ${ }^{\circ} \mathrm{C}(\mathrm{Ru} / \mathrm{IL} 6)$

\begin{tabular}{ccc}
\hline entry & $T\left[{ }^{\circ} \mathrm{C}\right]$ & $k\left[\mathrm{~mol} \mathrm{~L}^{-1} \mathrm{~h}^{-1}\right]$ \\
\hline 1 & 50 & 0.48 \\
2 & 60 & 0.60 \\
3 & 75 & 1.22 \\
4 & 90 & 2.57
\end{tabular}

After several uses as a hydrogenation catalyst, the particle size and state of agglomeration remains almost unchanged. The catalyst ionic liquid phase can be reused several times without a significant loss in catalytic activity.

The hydrogenation of toluene with Ru-NPs/BMI $\cdot \mathrm{NTf}_{2}, \mathbf{6}$, resulted in $85 \%$ conversion to methylcyclohexane (Table 2: entry 1; Figure 3 ). Higher-substituted arenes were significantly lower-hydrogenated (Table 1: entries 2-4). The hydrogenation of $o$-xylene and $p$-xylene to 1,2-dimethylcyclohexane (32\%) and 1,4-dimethylcyclohexane (31\%), respectively, gave identical results (Table 1: entries 2 and 4). The hydrogenation of $m$-xylene gave even an lowerhydrogenated product (Table 1: entry 3, 21\%). Interestingly, the bulky substituted substrate $t \mathrm{Bu}$-benzene presented a similar conversion (Table 1: entry 5, 20\%). Therefore, two methyl groups interfere in the hydrogenation of the aromatic ring, on the same level as one bulky substituent ( $t \mathrm{Bu}$ group), resulting in low conversions. This is a clear indication that the liquid-liquid arene hydrogenation by $\mathrm{Ru}(0)$ nanoparticles in ILs is highly sensitive to the steric effect imposed by alkyl groups on the aromatic ring, that is, akin to that usually observed with isolated metal nanoparticles. ${ }^{43}$

The properties of the catalytic system Ru-NPs/BMI $\cdot \mathrm{NTf}_{2}$ (6) were studied in more detail with the benchmark substrate toluene. For the determination of the activation energy for the hydrogenation of toluene, the initial rates of catalysis in the temperature range of $50-90{ }^{\circ} \mathrm{C}$ were used (Figures 4 and 5, Table 3) to generate an Arrhenius plot (Table 1: entries 1 and 6-8; Figure 6). Note that the first few minutes $(<5$ $\mathrm{min}$ ) were not considered in the analysis in order to guarantee a stable temperature equilibrium. Moreover, while pressurizing the Fischer-Porter bottle during the first ca. $20 \mathrm{~s}$, the pressure-fall in the gas reservoir is not linear. The extraction of the activation energy from the Arrhenius plot resulted in an apparent activation energy $E_{\mathrm{A}}=42.0 \mathrm{~kJ} \mathrm{~mol}^{-1}$ for the hydrogenation of toluene in the biphasic liquid-liquid system with Ru-NPs/ BMI $\cdot \mathrm{NTf}_{2}(\mathbf{6})$. Interestingly, this is similar to those activation energies reported for the transition-metalcatalyzed hydrogenation of toluene $\left(E_{\mathrm{A}}=40-50 \mathrm{~kJ} \mathrm{~mol}^{-1}\right)$ with solid-phase metal catalysts on solid supports. ${ }^{44-48}$

The calculated reaction order for the toluene concentration is 1.7 , and the reaction order of hydrogen was considered as zero at pressures $>4$ bar, since the reaction rate, in ionic liquids, is a mass-controlled process under a hydrogen pressure of 4 bar. $^{49}$

The variation of the imidazolium cations (BMI-DMI) and the corresponding anions $\left(\mathrm{NTf}_{2}-\mathrm{BF}_{4}\right)$ showed that the conversions for the ruthenium-catalyzed toluene hydrogenation are similar for most cases (entries 1, 14, and 15, Table 2). As mentioned for the system Ru-NPs/BMI $\cdot \mathrm{NTf}_{2}, \mathbf{6}$ (entry 1 , Table 2), the conversion is $85 \%$. This is in the same range

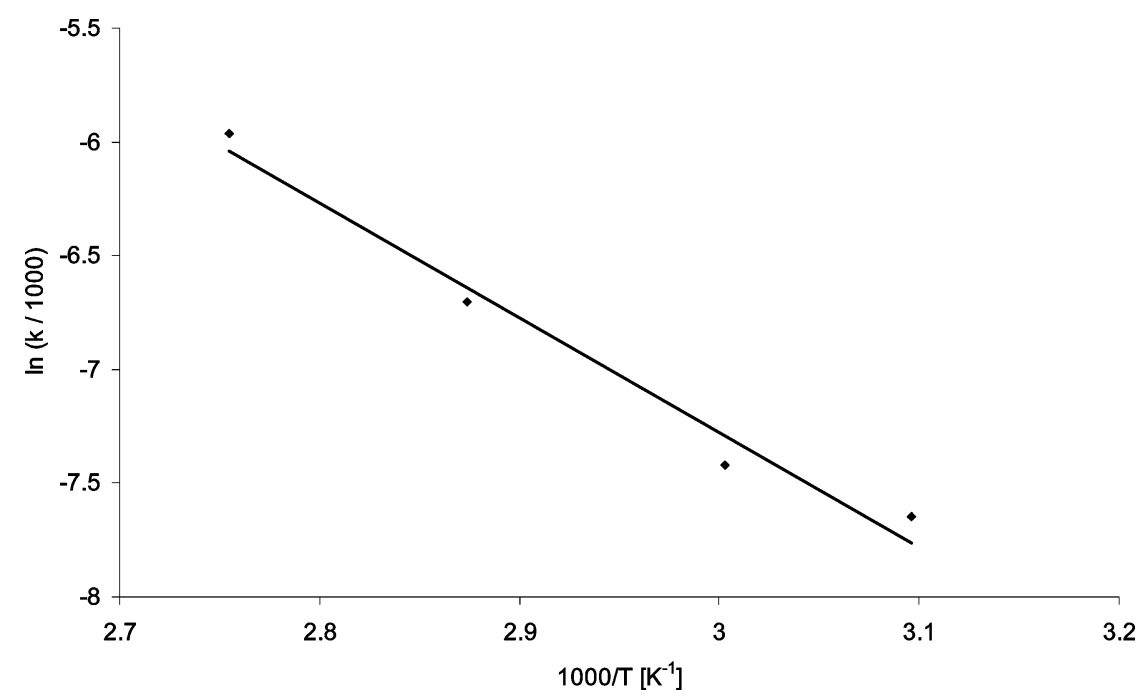

Figure 6. The Arrhenius plot of the catalytic hydrogenation of toluene in a biphasic liquid-liquid system with $\mathrm{Ru}-\mathrm{NPs} / \mathrm{BMI} \cdot \mathrm{NTf} 2(\mathbf{6})($ toluene/Ru $=200)$. The apparent activation energy for the hydrogenation is $E_{\mathrm{A}}=42 \mathrm{~kJ} \mathrm{~mol}^{-1}$. 
as the catalysis of the same substrate with Ru-NPs/DMI $\cdot \mathrm{BF}_{4}$, $8\left(76 \%\right.$, entry 14 , Table 2), and Ru-NPs/DMI $\cdot \mathrm{NTf}_{2}, 9(90 \%$, entry 15, Table 2). Interestingly, these systems (6, 8, and 9) are superior to $\mathrm{Ru}-\mathrm{NPs} / \mathrm{BMI} \cdot \mathrm{BF}_{4}, 7$, which results in only $40 \%$ methylcyclohexane under identical conditions (entry 13, Table 2). This stays in agreement with previous works with $\mathrm{Ru}-\mathrm{NPs} / \mathrm{BMI} \cdot \mathrm{BF}_{4}$ using a different ruthenium precursor, where a similar conversion was obtained. ${ }^{27}$ Interestingly, only trace amounts of methyl-cyclohexene were observed at very low toluene conversions $(<2 \%)$. This probably is a consequence of the higher solubility of the organic substrates, ${ }^{50}$ that is, toluene and partially hydrogenated arenes formed in the $\mathrm{BMI} \cdot \mathrm{NTf}_{2} \mathrm{IL}$, than in $\mathrm{BMI} \cdot \mathrm{BF}_{4}$ used earlier. ${ }^{27}$

\section{Conclusions}

A straightforward synthesis under mild conditions of catalytically active ruthenium nanoparticles in a variety of

(43) Fonseca, G. S.; Silveira, E. T.; Gelesky, M. A.; Dupont, J. Adv. Synth. Catal. 2005, 347, 847.

(44) Li, F.; Gates, B. C. J. Phys. Chem. C 2007, 111, 262.

(45) Jen, P. H.; Hsu, Y. H.; Lin, S. D. Catal. Today 2007, 123, 133.

(46) Thybaut, J. W.; Saeys, M.; Marin, G. B. Chem. Eng. J. 2002, 90, 117.

(47) Rousset, J. L.; Stievano, L.; Aires, F.; Geantet, C.; Renouprez, A. J.; Pellarin, M. J. Catal. 2001, 197, 335.

(48) Lindfors, L. P.; Salmi, T. Ind. Eng. Chem. Res. 1993, 32, 34.

(49) Fonseca, G. S.; Domingos, J. B.; Nome, F.; Dupont, J. J. Mol. Catal. A: Chem. 2006, 248, 10.

(50) Dupont, J.; Silva, S. M.; de Souza, R. F. Catal. Lett. 2001, 77, 131. imidazolium ionic liquids using the readily available ruthenium complex $\left[\operatorname{Ru}(\mathrm{COD})(2 \text {-methylallyl })_{2}\right]$ was disclosed. The TEM analysis revealed narrow size distributions between 2.1-3.5 $\mathrm{nm}$ and low agglomeration for the nanoparticles embedded in the imidazolium ILs, showing that nanoparticles with a smaller particle size are formed in the ILs containing the less coordinating $N$-bis(trifluoromethanesulfonyl)imidate anion. Also, after several uses as a hydrogenation catalyst, the particle size and state of agglomeration remains almost unchanged. The ruthenium nanoparticles in ionic liquids are active for the catalytic hydrogenation of several arenes in liquid-liquid biphasic systems. The catalyst ionic liquid phase can be reused several times without a significant loss in catalytic activity. Furthermore, the estimation of the activation energy $E_{\mathrm{A}}=42.0 \mathrm{~kJ} \mathrm{~mol}^{-1}$ for the hydrogenation of toluene is similar to those activation energies reported for transition-metal-catalyzed hydrogenation of toluene $\left(E_{\mathrm{A}}\right.$ $=40-50 \mathrm{~kJ} \mathrm{~mol}^{-1}$ ) with solid-phase catalysts on a solid support.

Acknowledgment. The Alexander-von-Humboldt Foundation is acknowledged for a Feodor-Lynen Postdoctoral Fellowship for M.H.G.P. For additional financial support, CAPES, CNPq, and PETROBRAS are acknowledged.

IC801014F 